ISSN 2179-345X

Licenciado sob uma Licença Creative Commons

\title{
Conselhos Setoriais como elementos de formulação de políticas públicas
}

\author{
Sector Councils as instruments of \\ public policy formulation
}

\begin{abstract}
Marcelo Ribeiro Losso
Doutorando em Direito pela Pontifícia Universidade Católica do Paraná (PUCPR), Curitiba, PR - Brasil, e-mail: marcelosso@gmail.com
\end{abstract}

\section{Resumo}

O presente trabalho trata do estudo dos Conselhos Setoriais como instrumentos de formulação de políticas públicas no Brasil. O Estado afasta-se da posição de império passando para a posição de consenso, interagindo com um número crescente de atores sociais. Os movimentos sociais no país nas últimas décadas, em especial aqueles que buscavam maior participação política, foram importantes para a abertura de canais de participação da sociedade civil na formulação de políticas públicas. Previsões constitucionais e legais permitem a participação da sociedade e o direcionamento das políticas públicas num sistema pautado no debate público, plural e paritário entre os diversos atores sociais. Os Conselhos Setoriais são instrumentos privilegiados de formulação das políticas públicas, 
contudo, apresentam limitações e desafios para que sejam alcançadas a eficácia e a efetividade desejadas para esses instrumentos.

Palavras-chave: Estado. Conselhos Setoriais. Políticas públicas. Movimentos sociais. Econômico e social.

\section{Abstract}

This paper is about the study of Sector Councils as instruments of public policy formulation in Brazil. The State deviates from the position of the Empire crossing to the consensus position, interacting with a growing number of social players. In recent decades the social movements in the country, specially the ones that sought for major political participation, were important for the opening of new channels of civil society participation in the formulation of public policies. Constitutional and legal foreknowledge allow the participation of the society and the public policy direction on a system guided upon public debate, plural and equal between the various social players. Sector Councils are the preferred instruments of public policies formulation, although they present limitations and challenges in order to achieve the desired efficiency and effectiveness for these instruments.

Keywords: State. Sector councils. Public policies. Social movements. Social and economic.

\section{Introdução}

Os diversos sistemas sociais contemporâneos (e.g.: político, econômico, científico, judicial, cultural, familiar, educacional, etc.) têm como característica o comportamento conforme o sistema daqueles que são por eles abrangidos. Contudo, aqueles que estão à margem desses sistemas apresentam comportamentos diversos do esperado pela sociedade, uma vez que desejam alterá-los para deles também participar.

Usualmente a primeira forma de demonstrar a insatisfação com a situação estabelecida pelo sistema é por meio dos movimentos sociais, que, num cenário de contestação e disputa, buscam espaços de participação. 
Nas últimas décadas, observa-se no Brasil um aumento das discussões sobre a participação da sociedade na formulação das políticas públicas. Essa participação pode ser representada por conflitos, litígios e disputas, típicas dos movimentos sociais. Contudo, desde a constituinte de 1988, foram abertos canais de participação dos diversos setores da sociedade, sendo que muitos desses acabaram sendo institucionalizados.

O presente trabalho pretende colaborar com o estudo da identificação e desenvolvimento da participação popular na formulação das políticas públicas no Brasil, por meio de canais institucionalizados. Para tanto, serão conceituados os movimentos sociais, o que pretendem e sua forma de agir. Será traçado, ainda, um histórico dos movimentos sociais que pleiteiam participação na formulação de políticas públicas nas últimas décadas no Brasil.

Além disso, serão listadas as principais previsões de participação popular, insertas na Constituição Federal de 1988. Também será abordada a conceituação de políticas públicas e como sua formulação tem sido descentralizada, contando inclusive com a participação popular. Os Conselhos Setoriais como instrumentos privilegiados de participação popular serão objeto de estudo, bem como sua composição, funções, forma de criação e principais características. Será também abordada a forma como eles estão estruturados no Brasil, e seu funcionamento como elementos de formulação de políticas públicas nas principais áreas de interesse da sociedade.

Os conselhos enfrentam uma série de obstáculos e desafios para alcançar a efetividade de suas ações, o que será também analisado. Por fim, serão trazidas as principais conclusões deste estudo.

\section{Movimentos sociais}

Segundo Maria da Glória Gohn, os movimentos sociais são ações coletivas de caráter sociopolítico, construídas por atores sociais pertencentes a diferentes classes e camadas sociais. Esses atores politizam suas demandas e criam um campo político de força social na sociedade civil. 
Suas ações estruturam-se a partir de repertórios criados sobre temas e problemas em situações de conflitos, litígios e disputas. As ações desenvolvem um processo social e político-cultural que confere uma identidade coletiva ao movimento, a partir de interesses comuns (GOHN, 1995). Buscam, em última análise, a alteração de condições econômicas, sociais e políticas da sociedade atual.

Entende-se tal conceituação como mais abrangente do que as clássicas trazidas por Alain Touraine, para quem os "movimentos sociais são a ação conflitante de agentes das classes sociais, lutando pelo controle do sistema de ação histórica" (TOURAINE, 1977, p. 336), e por Manuel Castells, que conceitua os movimentos sociais urbanos como "sistemas de práticas sociais contraditórias, isto é, que controvertem a ordem estabelecida a partir das contradições específicas da problemática urbana" (CASTELLS, 1976, p. 3).

Foram notórios no Brasil, nos anos 1970, os movimentos populares e sindicais, principalmente contra políticas oriundas do regime ditatorial. Somavam-se a isso a crescente urbanização e industrialização nacional.

Esses movimentos reivindicavam, prioritariamente, uma maior participação nas decisões públicas e a democratização do Estado (LÜCHMANN, 2002). Buscavam, numa época de cerceamento das liberdades, o direito de se associarem livremente em campos autônomos de participação e pretendiam fundar bases de organização social e política no país com vistas à garantia de novos direitos (SAMPAIO, 2006).

Aponta Sergio Blasbalg de Arruda Sampaio (2006, p. 39) que:

embora houvesse grande heterogeneidade dentre os atores que se somavam aos múltiplos movimentos existentes, as reivindicações comuns pelas eleições diretas, pela diminuição do custo de vida e por creches, moradia e emprego, amalgamavam uma bandeira coletiva da sociedade civil nos fins da década de 70 , que persistiria ao longo da década de 80 .

Na década de 1980 agravam-se a crise econômica e as dificuldades do regime militar. A alta do petróleo e das taxas de juros internacionais 
desequilibram o balanço brasileiro de pagamentos e eleva a inflação. Compromete, ainda, o modelo de crescimento econômico, baseado em financiamentos externos.

É nesse contexto da década de 1980 que se intensificam os movimentos de luta contra a ditadura militar e os esforços pela democratização do Estado. Nessa época, entre 1980 e 1981, são presos os líderes sindicais da região do $\mathrm{ABC}$ paulista, e ocorrem os atentados terroristas na sede da Ordem dos Advogados do Brasil (OAB) e no centro de convenções do Riocentro, no Rio de Janeiro. Em 25 de janeiro de 1984, na Praça da Sé, em São Paulo, ocorre um grande comício da campanha por eleições diretas para presidente, com participação de diversos partidos políticos e de lideranças sindicais, civis e estudantis. O evento conta com cerca de 300 mil pessoas.

Intensifica-se o debate sobre as políticas públicas, especialmente as de corte social, discutindo-se não só o padrão histórico que caracterizavam a realização das políticas sociais no País, mas também "a necessidade de democratização dos processos decisórios responsáveis pela definição de prioridades e modos de gestão de políticas e programas sociais" (RAICHELIS, 2010, p. 5). Isso favorece a redefinição das relações entre democratização e representação dos interesses populares nas decisões políticas.

A democratização ocorre a partir de 1985 (em 15 de janeiro de 1985, Tancredo Neves foi eleito presidente da república pelo Colégio Eleitoral, com José Sarney como vice-presidente, derrotando o candidato da situação, o deputado federal Paulo Maluf). Porém, Tancredo foi internado um dia antes da cerimônia de posse e após várias cirurgias faleceu em 21 de abril de 1985. Sarney assumiu a presidência no dia 15 de março de 1985. A redemocratização só se completa com a promulgação da Constituição Federal de 1988.

Porém, para o tema deste trabalho, é relevante resgatar o período da constituinte.

Os movimentos sociais, que antes se mostravam totalmente contrários ao Estado, passam a assumir outra atitude, mais propositiva, 
uma vez que são abertos espaços para discussões e apresentação de propostas e sugestões para o texto da nova Constituição. ${ }^{1}$

A existência de mecanismos de participação institucionalizados, como, por exemplo, as audiências públicas, impõe o encontro de diversos atores (movimentos sociais, organizações sindicais e profissionais, representantes do Estado) em fóruns, plenárias e encontros temáticos. Isso marca a transição da "participação movimentalista" para a "participação institucionalizada". Criam-se as condições para a ampliação da participação da sociedade na definição dos rumos das políticas públicas e para uma atuação coordenada entre Estado e a sociedade civil. Essa previsão de participação ficou retratada em diversos pontos na Constituição Federal de 1988, que serve de base para várias outras normas legais que instituem as diferentes formas de participação da sociedade.

\section{Previsões constitucionais de participação popular}

A participação popular equivale à interferência de um cidadão ou de representantes de grupos sociais, legitimados a agir em nome da coletividade. As diversas previsões constitucionais de participação popular decorrem do princípio fundamental inserto na previsão do parágrafo único do art. $1^{\circ}$ : Par. único: "todo o poder emana do povo, que o exerce por meio de representantes eleitos ou diretamente, nos termos desta constituição" (BRASIL, 1988). Assim, entende-se que, a par da garantia da democracia representativa, dá-se também ao povo a possibilidade de participar ativamente, de forma direta, do controle social da administração pública.

Sobre esse aspecto, Eduardo Kroeff Machado Carrion afirma que

\footnotetext{
Se antes o debate apontava para questões maniqueístas e reducionistas que "demonizavam" o Estado e viam na sociedade civil toda sorte de virtuosidades, com a Constituição Federal (CF) de 1988, a sociedade civil passou a ter novos contornos, assumindo um papel mais propositivo junto ao Estado (SAMPAIO, 2006, p. 39).
} 
quando se fala em controle social da administração pública, procura-se sugerir a idéia de um controle ao mesmo tempo político e social. Não apenas um controle de legalidade, mas principalmente um controle de mérito, de eficácia, de conveniência e de oportunidade do ato administrativo (CARRION, 1997, p. 83-84).

São diversas as previsões constitucionais de participação popular, cujas principais são retratadas a seguir.

No art. $5^{\circ}$, que trata dos direitos e garantias fundamentais, diversas previsões asseguram a participação popular, seja diretamente ou dando condições de acesso a dados e instrumentos de participação. No inciso XIV assegura-se a todos o acesso à informação; nos incisos XXXIII e XXXIV, garante-se o direito de receber informações dos órgãos públicos e o direito de petição; nos incisos LV e LXIX, garante-se o devido processo legal administrativo e o mandado de segurança contra ilegalidade ou abuso de poder de autoridade pública; no inciso LXXIII, garante-se o controle da conduta dos agentes públicos pelo cidadão por meio da ação popular. No $\S 2^{\circ}$ do artigo, afirma-se que além dessas garantias, não se exclui nenhuma outra decorrente dos princípios adotados pela constituição, ou dos tratados internacionais dos quais o país seja parte. Desse modo, abre-se uma gama de oportunidades de participação na administração pública.

No art. 10, assegura-se a participação dos trabalhadores e empregadores nos colegiados dos órgãos públicos nos quais seus interesses profissionais ou previdenciários sejam objeto de discussão.

No art. 14, estabelece-se ideia de soberania popular, o voto direto e secreto de igual valor para todos. Preveem-se o plebiscito, o referendo e a iniciativa popular, instrumentos da democracia participativa.

No âmbito municipal, o art. 29 dispõe que os municípios devem atender a diversos preceitos, dentre os quais destacam-se: o inciso XII, que garante a cooperação das associações representativas no planejamento municipal, e o inciso XIII, que prevê a iniciativa popular de projetos de lei de interesse específico do município, da cidade ou de bairros, por meio de manifestação de, pelo menos, $5 \%$ do eleitorado. 
No art. $31, \S 3^{\circ}$, garante-se a fiscalização das contas dos municípios, ao determinar que estas ficarão, durante 60 dias, anualmente, à disposição de qualquer contribuinte, para exame e apreciação, e poderão ter sua legitimidade questionada, nos termos da lei.

No capítulo referente à administração pública, prevê o art. 37, $\S 3^{\circ}$, a possibilidade de criação de outras formas de participação do usuário na administração pública, com destaque para: I) as reclamações relativas à prestação dos serviços públicos em geral, asseguradas a manutenção de serviços de atendimento ao usuário e a avaliação periódica, externa e interna, da qualidade dos serviços; II) o acesso dos usuários a registros administrativos e a informações sobre atos de governo, observado o disposto no art. $5^{\circ}$, X e XXXIII; e III) a disciplina da representação contra o exercício negligente ou abusivo de cargo, emprego ou função na administração pública.

Ao tratar do Poder Legislativo, mais especificamente das comissões, no art. 58, incisos II e IV, é prevista a participação da sociedade civil em audiências públicas e o recebimento de petições, reclamações, representações ou queixas de qualquer pessoa contra atos ou omissões das autoridades ou entidades públicas.

A participação popular de forma direta no processo legislativo é prevista no art. $61, \S 2^{\circ}$, que trata da iniciativa popular de projeto de lei.

$\mathrm{O}$ art. $74, \S 2^{\circ}$, traz a hipótese de atuação do cidadão como fiscal da conduta do administrador, ao prever a possibilidade de denunciar irregularidades ou ilegalidades ao Tribunal de Contas da União.

Ao tratar do Conselho da República, órgão superior de consulta do presidente da república, prevê-se a participação popular de seis cidadãos brasileiros natos, com mais de 35 anos de idade, nos termos do art. 89, VII.

Ao tratar do Poder Judiciário, assegura-se a participação de entidades de representação de classe na escolha do quinto constitucional para integrantes dos Tribunais Regionais Federais, Tribunais Estaduais e do Distrito Federal, nos termos do art. 94.

No que concerne à participação popular na gestão e na formulação de políticas públicas, são várias as previsões: I) assegura-se a participação dos produtores e trabalhadores rurais no planejamento da política 
agrícola nos termos do art. 187; II) dos trabalhadores, empregadores e aposentados nos órgãos colegiados relacionados à seguridade social, conforme art. 194, VII; III) da comunidade em relação às ações e serviços de saúde, conforme dispõe o art. 198, III; IV) da população, por meio de organizações representativas, na formulação das políticas e no controle das ações governamentais concernentes à assistência social, nos termos do art. 204, II; V) a gestão democrática do ensino público (art. 206, VI); VI) proteção e promoção do patrimônio cultural brasileiro, com a colaboração da comunidade, conforme art. 216, $\S 1^{\circ}$; VII) defesa e preservação do meio ambiente ecologicamente equilibrado, impondo-se ao poder público e à coletividade o dever de defendê-lo e preservá-lo para as presentes e futuras gerações (art. 225); VIII) possibilidade de participação de entidades não governamentais na assistência integral à saúde da criança, do adolescente e do jovem nos termos do art. 227, $\S 1^{\circ}$; IX) participação das comunidades indígenas, inclusive nos lucros, das atividades que aproveitem os recursos hídricos e minerais em suas terras, conforme previsão do art. $231, \S 3^{\circ}$.

Partindo das previsões insertas na Constituição Federal, diversas outras normas trazem previsões de participação popular, dentre as quais se pode citar a Lei de Responsabilidade Fiscal (Lei Complementar n. 101/00) que inovou ao tratar da transparência, controle e fiscalização. O art. 48 da Lei dispõe que:

art. 48. São instrumentos de transparência da gestão fiscal, aos quais será dada ampla divulgação, inclusive em meios eletrônicos de acesso público: os planos, orçamentos e leis de diretrizes orçamentárias; as prestações de contas e o respectivo parecer prévio; o Relatório Resumido da Execução Orçamentária e o Relatório de Gestão Fiscal; e as versões simplificadas desses documentos.

Parágrafo Único: A transparência será assegurada também mediante incentivo à participação popular e realização de audiências públicas, durante os processos de elaboração e de discussão dos planos, lei de diretrizes orçamentárias e orçamentos (BRASIL, 2000). 
Outro exemplo que merece ser citado é o Estatuto da Cidade (Lei n. 10.257/01), que assegura o direito de participação política dos movimentos populares e das organizações civis. O Estatuto prevê tal participação em diversos tópicos. Como exemplo pode-se citar o art. $2^{\circ}$, inciso II, que estabelece as diretrizes gerais da política urbana, arrolando dentre elas a "gestão democrática por meio da participação da população e de associações representativas dos vários segmentos da comunidade na formulação, execução e acompanhamento de planos, programas e projetos de desenvolvimento urbano" (BRASIL, 2001). Em seu art. 45, prevê que:

os organismos gestores das regiões metropolitanas e aglomerações urbanas incluirão obrigatória e significativa participação da população e de associações representativas dos vários segmentos da comunidade, de modo a garantir o controle direto de suas atividades e o pleno exercício da cidadania (BRASIL, 2001).

Constata-se, ainda, que no âmbito dos municípios foram institucionalizados diversos mecanismos de participação popular. Pode-se apontar como os mais notórios o Orçamento Participativo² e os Conselhos de Políticas Públicas.

Assim, em várias frentes abre-se a possibilidade de participação popular, em espaços que devem ser preenchidos por entidades da sociedade civil e/ou simplesmente pelos cidadãos.

\section{Políticas públicas}

Inicialmente, cumpre esclarecer o que se entende por políticas públicas. Podem ser consideradas "o conjunto de ações coletivas voltadas para a garantia dos direitos sociais, configurando um compromisso

2 O orçamento participativo permite que o cidadão debata e defina os destinos de uma cidade. Normalmente representa um percentual do orçamento público em que a população, de maneira participativa, decide as prioridades de investimentos em obras e serviços a serem realizados a cada ano, com os recursos do orçamento da prefeitura. 
público que visa dar conta de determinada demanda, em diversas áreas. Expressa a transformação daquilo que é do âmbito privado em ações coletivas no espaço público" (GUARESCHI, 2004, p. 180).

Essas ações podem ocorrer tanto no cenário técnico quanto político. Antonio Sergio Araujo Fernandes comenta que

costuma-se pensar o campo das políticas públicas unicamente caracterizado como administrativo ou técnico, e assim livre, portanto, do aspecto "político" propriamente dito, que é mais evidenciado na atividade partidária e eleitoral. Esta é uma meia verdade, dado que apesar de se tratar de uma área técnico-administrativa a esfera das políticas públicas também possui uma dimensão política uma vez que está relacionada ao processo decisório. Isto é, ao Estado é imperativo fazer escolhas sobre que área social atuar, onde atuar, por que atuar e quando atuar. Estas escolhas, por parte do Estado, que se transformam em decisões são condicionadas por interesses de diversos grupos sociais. Representam conquistas que se traduzem legalmente em direitos ou garantias defendidos pela sociedade. O Estado terá que intermediar e negociar estes interesses, na busca de estabelecer critérios de justiça social visando um discernimento político sobre suas funções sociais e qual o alcance delas (FERNANDES, 2007, p. 1).

Segundo Bolívar Lamounier (apud PROGRAMA URBIS, 2010), a compreensão do significado das políticas públicas corresponde a um duplo esforço: de um lado, entender a dimensão técnico-administrativa que a compõe buscando verificar a eficiência e resultados práticos para a sociedade das políticas públicas; de outro lado, reconhecer que toda política pública é uma forma de intervenção nas relações sociais em que o processo decisório condiciona e é condicionado por interesses e expectativas sociais.

É justamente nesse aspecto, da negociação de interesses e da intermediação do Estado quanto às demandas da sociedade, que entram como atores os diversos setores da sociedade civil, ora organizados como entidades, ora como movimentos sociais, ora ainda como partícipes nos diversos instrumentos colocados à disposição da sociedade, como é o caso dos Conselhos Setoriais. 


\section{Descentralização e participação da sociedade civil}

Pode-se afirmar que a sociedade civil brasileira tem participado, nas últimas décadas, de forma mais ampla e efetiva da administração pública, além do mero controle e fiscalização do poder público - vem interagindo com o Estado nas diferentes esferas de administração, na definição das prioridades e na elaboração dos planos de ação governamentais. Essa mudança de atitude ocorre por dois motivos: pelas mudanças na sociedade civil e pelas mudanças no Estado.

O Estado está mudando, pressionado pelas mudanças na sociedade. Segundo Diogo de Figueiredo Neto, a sociedade mudou principalmente no último quarto do século XX, em função do que o autor chama de polígono de mobilidades, representado pela mobilidade da informação, da produção financeira e social - esta última caracterizada pelo polifacetismo, decorrente da recombinação, multiplicação e diversificação sociais. Como decorrência dessas mudanças resulta a expansão do nível de consciência dos interesses e expansão da participação política (MOREIRA NETO, 2001).

O Estado, por sua vez, se transformou do modelo monoclasse, que atendia às classes dominantes, para atender os interesses das massas emergentes (Estado do bem-estar social e Estado socialista). Após a Segunda Guerra, esses tipos também passaram a dar sinais de exaustão, com a perda do peso relativo do Estado, que passou a enfrentar esvaziamento do poder no processo produtivo, acúmulo de déficits crescentes, falta de recursos para atender de forma eficiente as demandas sociais e a impossibilidade de aumentar indefinidamente a carga tributária. Como decorrência surge o Estado pluriclasse como organização política dominante.

Nos movimentos de adequação, a sociedade recobra o espaço político perdido e torna-se protagonista da política, fazendo despontar certos princípios, a saber: subsidiariedade, coordenação, privatização, publicização e consensualidade. 
No que concerne à consensualidade, o Estado tende a evoluir de um critério imperativo para outro consensual, no qual se busca o interesse público e o alcance da eficiência administrativa. Assim fica feita a distinção entre a democracia clássica - voltada à escolha dos governantes e a democracia do fim do século XX - voltada à escolha de como se quer ser governado.

Essa segunda forma vai se adensando nos diferentes países, tanto materialmente quanto formalmente, assim considerado pela multiplicação dos instrumentos de coordenação operativa entre sociedade e Estado (associações e parcerias). Tal consensualidade contribui decisivamente nas democracias contemporâneas aumentando a eficiência, diminuindo abusos (legalidade), promovendo a justiça, trazendo legitimidade às decisões, desenvolvendo o civismo e tornando os comandos estatais mais aceitáveis (ordem). Assim, a consensualidade traduz-se na alternativa preferível à imperatividade, que deve ser tida como exceção.

A respeito do tema, conclui Gustavo Henrique Justino de Oliveira:

a expansão do consensualismo na Administração pública vem acarretando a restrição de medidas de cunho unilateral e impositivo a determinadas áreas da ação administrativa. Isso provoca o florescimento da denominada Administração consensual, e a mudança de eixo do direito administrativo, que passa a ser orientado pela lógica da autoridade, permanentemente flexionada pela lógica do consenso (OLIVEIRA, 2005, p. 27, grifo nosso).

Assim, a administração pública passa da posição de império para a posição de consenso, onde há uma maior participação da sociedade. Exemplo dessa mudança é a implementação, ao longo das últimas décadas, dos vários conselhos, fóruns, câmaras setoriais, orçamentos participativos, etc. Somam-se a isso os Conselhos Gestores de Políticas Públicas, previstos na Constituição Federal e em diversas leis, em áreas como a saúde, a educação, a assistência social, etc. 


\section{Conselhos Setoriais}

Como já comentado, a participação da sociedade civil na discussão e implementação das políticas públicas ficou assegurada na Constituição Federal de 1988. Essa participação está representada nos Conselhos Setoriais, também denominados de conselhos gestores ou conselhos gestores de políticas públicas.

Embora entre os autores sejam encontradas algumas divergências quanto à composição dos conselhos - se esses podem ser compostos apenas por representantes do Estado ${ }^{3}$ ou necessariamente devem ter a participação popular ${ }^{4}$-, para efeitos deste trabalho consideram-se os conselhos mecanismos de deliberação pública criados por lei, com participação da sociedade civil, tendo, ainda, em diversos casos, a presença de representantes também de provedores de serviços privados (e.g.: sistemas nacionais de assistência social e saúde).

São, portanto, espaços públicos, usualmente com composição paritária entre membros do Estado e da sociedade civil, com natureza deliberativa. Ressalte-se que são diferentes dos conselhos comunitários, populares ou dos fóruns civis não governamentais, que são compostos apenas por membros da sociedade civil organizada, e funcionam como elementos de mobilização e de pressão, não possuindo assento institucional perante o poder público. Diferem ainda dos conselhos de "notáveis", compostos exclusivamente por especialistas, e que já foram usuais no âmbito público no passado.

3 Nesse sentido, Vanderlei Siraque comenta que "são órgãos colegiados criados pelo Estado, cuja composição e competência são determinadas pela lei que os instituiu. Assim, os conselhos poderão ser compostos apenas por agentes estatais ou incluir representantes da sociedade. Quanto à competência, podem ter função normativa, contenciosa, de polícia ou de planejamento e fiscalização das políticas públicas" (SIRAQUE, 2005, p. 122).

4 Maria da Glória Gohn afirma que "eles são compostos por representantes do poder público e da sociedade civil organizada e integram-se aos órgãos públicos vinculados ao Executivo" (GOHN, 2000, p. 175-201). 
Os conselhos têm por função construir políticas públicas setoriais, nos diversos níveis de gestão, seja municipal, estadual e federal, elegendo as prioridades da comunidade, com a discussão conjunta da sociedade civil e poder público, sobre os interesses coletivos. Permite, ainda, controlar, fiscalizar e monitorar a execução dessas políticas públicas.

A criação dos conselhos se dá por meio de lei e as decisões são tomadas por deliberação conjunta, tendo o voto valor igual para todos.

Partindo das observações de Clicia Maria Leite Nahra em trabalho intitulado "A Representação do Executivo Municipal nos Conselhos Gestores de Políticas Públicas", e Orlando Alves dos Santos Junior em trabalho denominado "Conselhos Municipais: um olhar sobre a experiência recente”, é possível traçar as principais características dessas entidades no âmbito municipal, entendidas como sendo apropriadas também para as demais esferas da administração pública, e que podem ser assim resumidas:

I) São órgãos plurais.

Embora institucionalizados, não são espaços exclusivos do governo e tampouco da sociedade civil. Segundo Luciana Tatagiba (2004 apud NAHRA, 2010, p. 3), “os conselhos são órgãos plurais, porque os representantes do governo e da sociedade civil negociam, disputam, compartilhando a responsabilidade pela produção das políticas públicas. Não se constituem em espaços do governo, tampouco da sociedade civil”.

II) São espaços de disputa.

Os conselhos são espaços de disputa, onde são defendidos interesses antagônicos e de diferentes atores (públicos, privados, corporativos, coletivos, individuais). Podem legitimar ou reverter o que está posto.

III) Pertencem à estrutura de gestão do Estado.

Os Conselhos Setoriais são estruturas de gestão do Estado, que tratam de matérias específicas. São permanentes e não representam necessariamente a força política que está no governo. São órgãos que estão 
ligados à estrutura do Poder Executivo, embora não estejam subordinados a ele.

IV) São autônomos ou semiautônomos em relação ao governo.

Embora ligados à estrutura do Estado, têm autonomia em suas atribuições para definir suas regras e funcionamento, o que deve ser feito com a participação de todos os segmentos sociais representados, inclusive o poder público.

V) São criados por Lei.

São criados por meio de leis e seus regimentos ou regulamentos são definidos pelos conselheiros (NAHRA, 2010). As leis de criação usualmente decorrem de previsões constantes na Constituição Federal.

VI) Buscam estabelecer um novo padrão de relação entre Estado e sociedade.

Os conselhos possibilitam o acesso da população às instâncias de decisões políticas. Diferem das tradicionais formas de acesso que meramente recebem reclamações e solicitações, de questionável eficácia.

VII) São órgãos deliberativos.

Em geral são órgãos deliberativos, abrangentes e permanentes. Não se restringem à formulação de sugestões ou ao encaminhamento de demandas. Deliberam sobre as diretrizes das políticas públicas referentes ao tema específico, aprovando a normatização, a regulação das ações governamentais, a proposta orçamentária.

VIII) São temáticos.

Isto porque têm área específica de atuação, ligada a determinadas políticas públicas (e.g.: saúde, educação, assistência social, criança e adolescente, emprego, meio ambiente, etc.). 
IX) São de caráter semirrepresentativo.

Não há eleição direta, em sufrágio universal, dos seus integrantes. A participação normalmente é voluntária e não remunerada. Podem ser substituídos sempre que as organizações sociais assim decidirem.

X) Têm composição paritária.

A composição usualmente é paritária entre governo e sociedade (relação de 50\% para cada parte). Em alguns casos, dependendo dos atores envolvidos, a composição é tripartite (e.g.: Conselhos de Saúde, onde a divisão é tripartite, na proporção de $50 \%$ de representantes dos usuários (organizações da sociedade civil), 25\% de representantes do governo e 25\% de representantes das prestadoras de serviço e organizações representantes dos trabalhadores do setor).

Clicia Maria Leite Nahra sinteteza os conselhos "como canais institucionais, plurais, permanentes, autônomos, formados por representantes da sociedade civil e sociedade política, cuja atribuição é a de propor políticas públicas, fiscalizá-las, controlá-las e deliberar sobre elas, sendo órgãos da gestão pública vinculados à estrutura do Poder Executivo, ao qual cabe garantir a sua permanência" (NAHRA, 2010, p. 4).

\section{Conselhos Setoriais nas diversas áreas de formulação de políticas públicas}

Seguindo as previsões constitucionais, aponta-se a existência de Conselhos Setoriais vinculados às seguintes áreas: direitos dos trabalhadores (art.10); seguridade social (art.194, VII) (saúde - art. 198, III -, previdência e assistência social); educação (art. 205); proteção do patrimônio cultural brasileiro (art. 216, $\S 1^{\circ}$ ); meio ambiente (art. 225); e formação da criança e do adolescente $\left(227, \S 1^{\circ}\right.$ e $\left.\S 7^{\circ}\right)$.

Luciane Schulz Fonseca (2008, p. 169-180) arrola diversos conselhos criados por Leis, apontando, ainda, suas respectivas leis de criação: 
a) Conselho Curador do Fundo de Garantia do Tempo de Serviço (CCFGTS) (Lei n. 8.036/90) (BRASIL, 1990b);

b) Conselho Deliberativo do Fundo de Amparo ao Trabalhador (CODEFAT) (Lei n. 7.998/90) (BRASIL, 1990a);

c) Conselho Nacional de Assistência Social (CNAS) (Lei n. 8.742/93) (BRASIL, 1993);

d) Conselho Nacional de Previdência Social (CNPS) (Lei n. 8.213/91) (BRASIL, 1991a);

e) Conselhos de Saúde (Lei n. 8.142/90, que dispõe sobre a participação da comunidade na gestão do Sistema Único de Saúde SUS - no $\S 2^{\circ}$ do art. $1^{\circ}$ traz a definição e a função dos Conselhos de Saúde em cada esfera do governo). A partir dessa previsão, foram formados Conselhos de Saúde em todas as esferas da administração pública (BRASIL, 1990d);

f) Conselho Nacional do Meio Ambiente (CONAMA) (Lei n. 6.938/81) (BRASIL, 1981);

g) Fundo Nacional de Desenvolvimento Florestal (FNDF), que possui um Conselho Consultivo (Lei n. 11.284/06) (BRASIL, 2006).

No que se refere à participação da sociedade na formação da criança e do adolescente, a Lei n. 8.069/90 dispõe sobre os Conselhos Tutelares e faz referência aos Conselhos Municipais, Estaduais e Nacional dos direitos da criança e do adolescente (BRASIL, 1990c). Com base nisso, em âmbito federal a Lei n. 8.242/1991 criou o Conselho Nacional dos Direitos da Criança e do Adolescente (CONANDA), cabendo aos demais entes a criação de seus respectivos conselhos (BRASIL, 1991b).

Quanto à participação da sociedade na educação, em decorrência do disposto no art. 205 da Constituição Federal, a educação é dever do Estado e da família. A sociedade civil organizada tem participado da comunidade escolar por meio das Associações de Pais e Mestres e dos Conselhos Escolares, com apoio dos governos federal e estadual. Como exemplos de Conselhos Gestores no segmento educação, pode-se citar: Conselhos de Alimentação Escolar e Conselhos do FUNDEF. 
No âmbito da Assistência Social, destaca-se a existência dos Conselhos Municipais de Assistência Social voltados aos programas de assistência social envolvendo crianças (creches), idosos, portadores de deficiências físicas, entre outros.

Destarte, em setores essenciais da sociedade a existência dos Conselhos Setoriais é já há anos uma realidade, e possibilita à sociedade civil eleger com o poder público as prioridades que devem ser atendidas.

\section{Conselhos Setoriais como elementos de formulação de políticas públicas}

Dadas as características dos conselhos, entende-se que são organismos institucionalizados de participação popular que viabilizam a discussão, em arenas paritárias, dos diversos interesses em pauta, possibilitando a interação do governo com a sociedade, nesta entendida todos os partícipes (e.g.: trabalhadores e empregadores, usuários e fornecedores, etc.).

Os conselhos possibilitam a mediação de conflitos e a construção de consensos, após negociações e deliberações conjuntas. Isso resulta num resgate dos diversos atores sociais para participar do sistema institucionalizado, e diminuir os movimentos dos setores usualmente excluídos da formulação das políticas públicas. Pode-se apontar que isso decorre inicialmente do reconhecimento das demandas dos demais atores como legítimas, tendo a mediação do poder público.

O contato desses atores entre si e com os dirigentes e técnicos do governo propicia o conhecimento da realidade e das limitações administrativas (inclusive quanto à burocracia, e limitações legais e orçamentárias) bem como o estabelecimento de parcerias e alianças entre os atores, inclusive entre segmentos sociais, técnicos e governamentais.

Outro aspecto é o estabelecimento de um canal adequado para a comunicação, a construção da opinião pública e a tomada de decisões em torno das opções disponíveis quanto às políticas sociais, de modo que essas escolhas estejam mais próximas dos interesses do conjunto de atores. 
Orlando Alves dos Santos Junior (2010) comenta que "a dinâmica dos conselhos tem proporcionado pequenos aprendizados nessa direção, seja por meio da incorporação de demandas específicas dos grupos populares na lógica e na ação do poder público, seja por meio das experiências de participação nas decisões relativas à gestão das políticas sociais". Como exemplo, ele cita o credenciamento ou descredenciamento de convênios com o setor privado e entidades sem fins lucrativos, a definição de regras normativas para os serviços públicos e a definição de prioridades de investimentos. Outro exemplo, talvez o aspecto mais concreto e disseminado seria a limitação imposta ao governo pelas organizações sociais, pelo controle sobre a aplicação dos fundos federais e da imposição de maiores barreiras à apropriação privada dos recursos públicos, evitando clientelismo e corrupção.

\section{Desafios à efetividade dos conselhos}

Se os conselhos representam um canal privilegiado de participação popular e de diminuição de tensões sociais pela possibilidade de negociação e de formulação de políticas públicas, por outro lado enfrentam uma série de obstáculos e desafios para alcançar a efetividade de suas ações. Dentre as dificuldades enfrentadas pode-se apontar:

a) falta de consciência cívica da população, que não raramente tem a convicção de que somente o governo deve resolver os problemas públicos;

b) ausência de tradição de cidadania. A falta de conhecimento dos direitos inibe a população de participar. Não é comum a atitude fiscalizadora do cidadão - ao contrário, usualmente as pessoas não querem se envolver, se preocupar com os problemas públicos, salvo quando estes as atingem diretamente;

c) existência relativamente recente dos conselhos, que dada a falta de exercício prático (e às vezes a sua inexistência) e o desconhecimento de suas possibilidades por parte da maioria da 
população, pode resultar em espaço livre a ser ocupado e utilizados como mecanismo político dos ocupantes do poder;

d) criação de entidades com o pensamento individualista, com pessoas assumindo a direção de uma entidade privada, ou ocupando vagas em conselhos representativos, no intuito de auferir vantagem em proveito próprio;

e) parcelas significativas dos segmentos sociais, principalmente os mais vulneráveis, e, portanto, menos articulados, não têm sua agenda de demandas representada nessas arenas públicas, por não possuírem vínculos associativos com organizações sociais que a representem;

f) resistência das autoridades governamentais. Muitos governantes não veem com bons olhos a participação popular na formulação de políticas públicas e no controle da administração. Para alguns a participação popular incomoda, atrapalha as pretensões previamente definidas. Não raro demonstram antipatia pela participação da sociedade civil. Outros não se dispõem ou não estão preparados para ouvir a opinião da comunidade;

g) limitação na capacidade decisória dos Conselhos Municipais, pela carência de garantias de acesso a: a) informações (os representantes da população têm que ter igualdade de condições de acesso às informações, que normalmente estão disponíveis nos órgãos públicos); b) aos processos de fiscalização e tomada de decisão em torno da gestão das políticas públicas; c) meios de divulgação das decisões para a sociedade; d) estrutura de funcionamento; e) uma metodologia para seu funcionamento;

h) risco de transformação dos conselhos em estruturas burocráticas formais, subordinadas às rotinas administrativas dos órgãos públicos, limitando-os a responder aos procedimentos da administração, como aprovação de contratos e prestações de contas exigidos nos convênios. Boa parte dos conselhos não possui uma agenda política de médio e longo prazo capaz de instituir 
uma pauta de discussão mais estratégica para a gestão das políticas públicas (SANTOS Jr., 2010);

i) ausência de uma definição mais precisa das competências e atribuições dos conselhos;

j) ausência de instrumentos legais de apoio às suas deliberações. O fato de as decisões dos conselhos terem caráter deliberativo não garante sua implementação, pois não há estruturas jurídicas que deem amparo legal e obriguem o Executivo a acatar as decisões dos conselhos (principalmente quando essas decisões contrariam os interesses dominantes) (GOHN, 2000). Essa é uma das principais críticas aos conselhos instituídos principalmente no âmbito dos municípios, onde se denota que há participação popular, com a exposição dos diferentes interesses, negociações e deliberações. Contudo, a efetiva implantação das políticas muitas vezes não ocorre porque não há instrumentos legais que obriguem o administrador público a efetivar as deliberações dos conselhos.

\section{Conclusão}

Os movimentos sociais buscam a alteração de condições econômicas, sociais e políticas da sociedade atual. Suas ações se desenvolvem em meio a um ambiente de conflitos, litígios e disputas.

No Brasil, principalmente durante o regime militar, eclodiram diversos movimentos. Com a redemocratização e notadamente com a convocação da Constituinte para a participação da sociedade, por meio de apresentação de sugestões e demandas ou pela participação em audiências públicas, inaugura-se uma nova fase no relacionamento do poder público com a sociedade. O Estado tende a evoluir de um critério imperativo para outro consensual, no qual se busca o interesse público e o alcance da eficiência administrativa. 
Na Constituição de 1988 é expressamente prevista e assegurada a participação popular em diversas áreas de grande relevância e alcance social (BRASIL, 1988). A Constituição prevê, em vários dispositivos, a participação popular na formulação de políticas públicas e no controle da administração. Essa participação é representada, principalmente, pelos Conselhos Setoriais, o que de certa forma diminui a tensão social e faz com que parte dos movimentos sociais se organize em entidades representativas para agirem como atores nas arenas de discussão de políticas públicas.

Assim, os conselhos assumem crucial importância para a efetividade de direitos sociais, posto que deliberam sobre as políticas públicas, transformando o orçamento em ações, instrumentos e serviços concretos para a sociedade.

Contudo, embora representem a efetiva participação popular no direcionamento das políticas públicas, tais conselhos enfrentam, ainda, uma série de obstáculos para alcançar eficácia e efetividade na área de atuação e reconhecimento da sociedade. Faz-se necessário aprimorar tais instrumentos dando peso político a essa representação. Entende-se que para alcançar esse objetivo são necessários vários avanços no âmbito dos indivíduos, da sociedade e do Estado.

No âmbito dos indivíduos é necessária uma cultura de consciência cívica, de participação e de sentimento de corresponsabilidade entre sociedade e governo. Deve-se fomentar uma tradição de cidadania, afastar o pensamento individualista, com a assunção de cargos e vagas em órgãos representativos, no intuito de auferir benefícios em proveito próprio.

A sociedade deve ser esclarecida quanto à existência e funcionamento dos conselhos, conhecendo, também os limites de sua atuação. Deve buscar representar as mais diversas parcelas da sociedade, principalmente as mais vulneráveis e menos articuladas. Os agentes políticos devem conhecer a existência dos conselhos e respeitar sua atuação, ouvindo a opinião da comunidade.

Ao Estado cabe estabelecer formas de resguardar a aplicação das deliberações dos conselhos; ampliar a capacidade decisória dos mesmos; viabilizar igualdade de condições de acesso às informações, processos, meios 
de divulgação das decisões e estrutura de funcionamento para os diversos atores sociais. Deve zelar pela autonomia dos conselhos, a fim de evitar que estes se transformem em estruturas burocráticas formais, inclusive com uma definição mais precisa das competências e atribuições dos mesmos.

Por fim, de nada adianta a previsão de participação popular e a composição de conselhos e a interveniência dos diversos atores na elaboração de políticas públicas, se não for estabelecido um aparato legal de amparo às decisões colegiadas, que obriguem o administrador público a efetivar as deliberações dos conselhos.

\section{Referências}

BRASIL. Constituição (1988). Constituição: República Federativa do Brasil. Brasília, DF: Senado Federal, 1988.

BRASIL. Lei Complementar n. 101/00 de 4 de maio de 2000. Estabelece normas de finanças públicas voltadas para a responsabilidade na gestão fiscal e dá outras providências. Diário Oficial [da] República Federativa do Brasil, Poder Legislativo, Brasília, DF, 4 maio 2000. Disponível em: <http://www.planalto.gov. br/ccivil_03/Leis/LCP/Lcp101.htm>. Acesso em: 27 jul. 2010.

BRASIL. Lei Federal n. 6.938 de 31 de agosto de 1981. Dispõe sobre a Política Nacional do Meio Ambiente, seus fins e mecanismos de formulação e aplicação, e dá outras providências. Diário Oficial [da] República Federativa do Brasil, Poder Legislativo, Brasília, DF, 31 ago. 1981. Disponível em: <http://www.planalto.gov.br/ccivil_03/leis/16938.htm〉. Acesso em: 27 jul. 2010.

BRASIL. Lei Federal n. 7.998 de 11 de janeiro de 1990. Regula o Programa do Seguro-Desemprego, o Abono Salarial, institui o Fundo de Amparo ao Trabalhador (FAT), e dá outras providências. Diário Oficial [da] República Federativa do Brasil, Poder Legislativo, Brasília, DF, 11 jan. 1990a. Disponível em: 〈http://www.planalto.gov.br/ccivil_03/leis/L7998.htm〉. Acesso em: 27 jul. 2010. 
BRASIL. Lei Federal n. 8.036 de 11 de maio de 1990. Dispõe sobre o Fundo de Garantia do Tempo de Serviço, e dá outras providências. Diário Oficial [da] República Federativa do Brasil, Poder Legislativo, Brasília, DF, 11 maio 1990b. Disponível em: <http://www.planalto.gov.br/ccivil_03/leis/18036consol. htm>. Acesso em: 27 jul. 2010.

BRASIL. Lei Federal n. 8.069 de 13 de julho de 1990. Dispõe sobre o Estatuto da Criança e do Adolescente e dá outras providências. Diário Oficial [da] República Federativa do Brasil, Poder Legislativo, Brasília, DF, 13 jul. 1990c. Disponível em: <http://www.planalto.gov.br/ccivil_03/leis/18069.htm>. Acesso em: 27 jul. 2010.

BRASIL. Lei Federal n. 8.142 de 28 de dezembro de 1990. Dispõe sobre a participação da comunidade na gestão do Sistema Único de Saúde (SUS) e sobre as transferências intergovernamentais de recursos financeiros na área da saúde e dá outras providências. Diário Oficial [da] República Federativa do Brasil, Poder Legislativo, Brasília, DF, 28 dez. 1990d. Disponível em: <http://www.planalto.gov.br/ccivil_03/leis/18142.htm>. Acesso em: 27 jul. 2010.

BRASIL. Lei Federal n. 8.213 de 24 de julho de 1991. Dispõe sobre os Planos de Benefícios da Previdência Social e dá outras providências. Diário Oficial [da] República Federativa do Brasil, Poder Legislativo, Brasília, DF, 24 jul. 1991a. Disponível em: <http://www.planalto.gov.br/ccivil_03/leis/18213cons.htm>. Acesso em: 27 jul. 2010.

BRASIL. Lei Federal n. 8.242 de 12 de outubro de 1991. Cria o Conselho Nacional dos Direitos da Criança e do Adolescente (Conanda) e dá outras providências. Diário Oficial [da] República Federativa do Brasil, Poder Legislativo, Brasília, DF, 12 out. 1991b. Disponível em: <http://www.planalto.gov.br/ccivil_03/leis/L8242.htm>. Acesso em: 27 jul. 2010.

BRASIL. Lei Federal n. 8.742 de 7 de dezembro de 1993. Dispõe sobre a organização da Assistência Social e dá outras providências. Diário Oficial [da] República Federativa do Brasil, Poder Legislativo, Brasília, DF, 7 dez. 1993. Disponível em: 〈http://www.planalto.gov.br/ccivil_03/leis/18742.htm>. Acesso em: 27 jul. 2010. 
BRASIL. Lei Federal n. 10.257 de 10 de julho de 2001. Regulamenta os arts. 182 e 183 da Constituição Federal, estabelece diretrizes gerais da política urbana e dá outras providências. Diário Oficial [da] República Federativa do Brasil, Poder Legislativo, Brasília, DF, 10 jul. 2001. Disponível em: <http://www.planalto.gov.br/ccivil_03/Leis/LEIS_2001/L10257.htm>. Acesso em: 27 jul. 2010.

BRASIL. Lei Federal n. 11.284 de 2 de março de 2006. Dispõe sobre a gestão de florestas públicas para a produção sustentável; institui, na estrutura do Ministério do Meio Ambiente, o Serviço Florestal Brasileiro - SFB; cria o Fundo Nacional de Desenvolvimento Florestal - FNDF; altera as Leis ${ }^{\text {os }} 10.683$, de 28 de maio de 2003, 5.868, de 12 de dezembro de 1972, 9.605, de 12 de fevereiro de 1998, 4.771, de 15 de setembro de 1965, 6.938, de 31 de agosto de 1981, e 6.015, de 31 de dezembro de 1973; e dá outras providências. Diário Oficial [da] República Federativa do Brasil, Poder Legislativo, Brasília, DF, 2 mar. 2006. Disponível em: <http://www.planalto.gov.br/ccivil_03/_ato2004-2006/2006/ lei/111284.htm>. Acesso em: 27 jul. 2010.

CARRION, E. K. M. Apontamentos de direito constitucional. Porto Alegre: Livraria do Advogado, 1997.

CASTELLS, M. Movimientos sociales urbanos. 2. ed. Buenos Aires: Siglo Veintiuno, 1976.

FERNANDES, A. S. A. Políticas públicas: definição, evolução e o caso brasileiro na política social. In: DANTAS, H.; MARTINS Jr., J. P. (Org.). Introdução à política brasileira. São Paulo: Paulus, 2007. Disponível em: <http://serv01.informacao. andi.org.br/b6d71ce_114f59a64cd_-7fcc.pdf >. Acesso em: 26 jul. 2010.

FONSECA, L. S. Gestão participativa. Curitiba: Ed. da UFPR, 2008.

GOHN, M. da G. Movimentos e lutas sociais na história do Brasil. São Paulo: Loyola, 1995.

GOHN, M. da G. O papel dos conselhos gestores na gestão urbana. In: RIBEIRO, A. C. T. (Org.). Repensando a experiência urbana da América Latina: questões, conceitos e valores. Buenos Aires: CLACSO, 2000. p. 175-201. 
GUARESCHI, N. et al. Problematizando as práticas psicológicas no modo de entender a violência. In: STREY, M. N. et al. (Org.). Violência, gênero e políticas públicas. Porto Alegre: EDIPUCRS, 2004.

LÜCHMANN, L. H. H. Possibilidades e limites da democracia deliberativa: a experiência do orçamento participativo de Porto Alegre. 2002. 215 f. Tese (Doutorado em Ciências Sociais) - Universidade Estadual de Campinas, Campinas, 2002.

MOREIRA NETO, D. de F. Mutações do direito administrativo. 2. ed. Rio de Janeiro: Renovar, 2001.

NAHRA, C. M. L. A representação do executivo municipal nos conselhos gestores de políticas públicas. Porto Alegre: Prefeitura Municipal de Porto Alegre. Disponível em: <http://lproweb.procempa.com.br/pmpa/prefpoa/observatorio/usu_doc/executivo_conselhos.pdf $>$. Acesso em: 28 jul. 2010.

OLIVEIRA, G. J. de. A arbitragem e as parcerias público-privadas. Revista Eletrônica de Direito Administrativo Econômico, Salvador, n. 2, 2005. Disponivel em: <http://www.direitodoestado.com/revista/REDAE-2-MAIO- 2005-GUSTAVO\%20JUSTINO.pdf $>$. Acesso em: 12 maio 2007.

PROGRAMA URBIS. Cursos temáticos: construção de política pública. Disponível em: <http://www.urbisnetwork.com/documents/CT-ConstrucaodePoliticasPublicas.pdf $\rangle$. Acesso em: 27 jul. 2010.

RAICHELIS, R. Democratizar a gestão das políticas sociais: um desafio a ser enfrentado pela sociedade civil. Serviço social e saúde: formação e trabalho profissional. Disponível em: <http://www.fnepas.org.br/pdf/servico_social_saude/ texto1-4.pdf $>$. Acesso em: 23 jul. 2010.

SAMPAIO, S. B. de A. O olhar governamental sobre os conselhos de políticas públicas: o caso do Conselho Municipal de Saúde de São Paulo no período de 2001 a 2004. 2006. 179 f. Dissertação (Mestrado em Administração Pública e Governo) Escola de Administração de Empresas de São Paulo da Fundação Getúlio Vargas, São Paulo, 2006. Disponível em: <http://bibliotecadigital.fgv.br/dspace/bitstream/handle/10438/2396/155059.pdf?sequence=2>. Acesso em: 23 jul. 2010. 
SANTOS Jr.., O. A. dos. Conselhos municipais: um olhar sobre a experiência recente. Disponível em: <http://www.fase.org.br/v2/admin/anexos/acervo/10_ Orlando\%20Junior-27.doc >. Acesso em: 28 jul. 2010.

SILVA, J. A. da. Curso de direito constitucional positivo. 9. ed. São Paulo: Malheiros, 1992.

SIRAQUE, V. Controle social da função administrativa do Estado: possibilidades e limites na Constituição de 1988. São Paulo: Saraiva, 2005.

TOURAINE, A. Os movimentos sociais. In: FORACCHI, M. M.; MARTINS, J. de S. Sociologia e sociedade. Rio de Janeiro: Livros Técnicos e Científicos, 1977.

Recebido: 16/03/2011

Received: 03/16/2011

Aprovado: 20/05/2011 Approved: 05/20/2011 